\title{
Laboratório de design social Covid-19: um experimento de design participativo na pandemia
}

\section{Covid19 social design laboratory: a participatory design experiment in the pandemic}

Agnes Milen Guerra, Bruna Cibelle de Andrade Abreu, Carlos Delano Rodrigues, Israel Lucas Sousa Silva, Jackeline Mendes Pereira, Rafael Ricarte de Souza

design participativo, design social, infraestruturação, covid-19

\begin{abstract}
A pandemia do covid-19 impôs uma série de desafios urgentes para a sociedade. Nesse sentido, em março de 2020, foi constituído o Laboratório de Design Social Covid-19, um experimento interdisciplinar de design social e participativo que uniu acadêmicos e profissionais das áreas de design, da comunicação, do direito e da saúde com o intuito de reunir e compartilhar informações que fossem relevantes e confiáveis para prevenir a contaminação pelo coronavírus, assim como projetar e divulgar medidas que auxiliassem as pessoas a lidarem com a complexidade imposta pelo período de distanciamento social, formando assim uma rede de apoio e informação. Este artigo tem como objetivo apresentar o estudo de caso sobre sua formação, a constituição de públicos em torno de um interesse comum, a construção de uma infraestrutura social e técnica e o alargamento de seu escopo inicial para a criação do Quentinha Solidária, projeto de apoio às pessoas em situação de rua na cidade de São Luís, Maranhão e o papel do design da informação nesse processo.
\end{abstract}

participatory design, social design, infrastructuring, covid-19

The covid-19 pandemic imposed a series of urgent challenges to society. As such, on March 20, the Lab of Social Design Covid-19 was constituted, an interdisciplinary experiment of social and participatory design which gathered academics and professionals from areas such as design, communication, law and healthcare in order to gather and share relevant and reliable information to prevent the contamination by the coronavirus, as well as to design and disclose measures that helped people dealing with the complexity imposed by the period of social distancing, creating a support and information network. This article aims to present this case study about its formation, the constitution of the public around a common interest, the construction of social and technical infrastructure and the enlargement of its initial scope for the creation of the Quentinha Solidária, a project to support people who are currently living in the streets of São Luís, Maranhão and the role of information design in this process.

\section{O laboratório de Design Social}

O Laboratório de Design Social (Labdes) foi inspirado inicialmente no formato dos Laboratórios Vivos (Living Labs) que se referem a ambientes que exploram a cocriação e apropriação de inovações por participantes que, muitas vezes, atuam em um ambiente comunitário e devem envolver também as partes interessadas pelas soluções a serem propostas (Ballon \&

Schuurman, 2016).

Anais do $10^{\circ} \mathrm{CIDI}$ e $10^{\circ} \mathrm{CONGIC}$

Kelli C.A.S. Smythe, Rafael de Castro Andrade (orgs.)

Sociedade Brasileira de Design da Informação - SBDI

Curitiba | Brasil | 2021
Proceedings of the $10^{\text {th }} \mathrm{CIDI}$ and $10^{\text {th }}$ CONGIC

Kelli C.A.S. Smythe, Rafael de Castro Andrade (orgs.)

Sociedade Brasileira de Design da Informação - SBDI Curitiba | Brazil | 2021 
Estas iniciativas estão apoiadas em um modelo de cooperação no qual os recursos e oportunidades são compartilhados com o foco na busca de soluções para problemas que não possuem respostas claras para, assim, proporcionar aos participantes o alcance de seus objetivos. São ambientes (não necessariamente físicos), onde pessoas (especialistas e não especialistas) interagem e trabalham de maneira ativa, projetando e implementando atividades experimentais cooperativas que resultem em aprendizado coletivo e compreensão compartilhada (Boronowsky et al. 2006 apud Concilio \& Riso, 2016).

O modelo de Laboratório de Design Social aqui apresentado foi conduzido pela primeira vez na região do Desterro, centro histórico de São Luís, que funcionou como uma "Assembleia Projetual" para levantar e discutir questões de interesse comum às pessoas que vivenciam o cotidiano do bairro (Delano Rodrigues, 2020).

Esses Laboratórios se apropriam dos modelos de oficinas (workshops) a fim de proporcionar o conhecimento necessário para conseguir alcançar seus objetivos e unem formas de colaboração presencial e não-presencial (Delano Rodrigues, 2020).

A "Assembleia Projetual" foi concebida como um espaço simbólico, montado a partir de questões de interesse comum, onde designers especialistas e amadores se juntam a outras partes interessadas para dialogar e projetar soluções, especular e prototipar ideias, definir objetivos alinhados a um tempo de implementação pré-determinado, buscar recursos para realizá-los, ao mesmo tempo em que são desenvolvidos vínculos entre as pessoas e a assembleia (Delano Rodrigues, 2020).

O Labdes - Desterro (Figura 1) funcionou de forma presencial no bairro do Desterro em dois momentos, entre os anos de 2016 e 2017, e proporcionou a implementação de duas das ideias propostas pelos participantes (Delano Rodrigues, 2020).

O Labdes Covid - 19, surgiu após a paralisação das aulas da Universidade Federal do Maranhão (UFMA), em 17 de março de 2020, devido às incertezas impostas pelo aparecimento dos primeiros casos de Covid-19 no estado do Maranhão. As primeiras conversas para compor uma Assembleia Projetual aconteceram em 24 de março e foram estabelecidas entre um dos professores do curso de Design, na disciplina de Projeto Gráfico II na UFMA, juntamente com uma das discentes e representante do Centro Acadêmico de Design na instituição. 
Figura 1: Assembleia Projetual do Labdes - Desterro

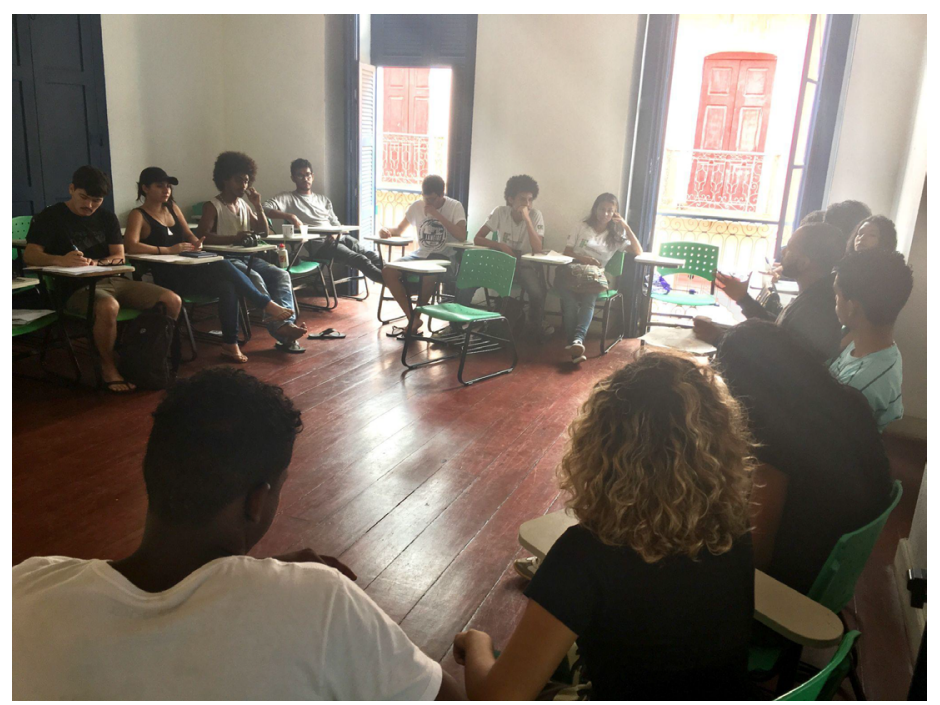

Considerando a relevância de compartilhar iniciativas de design participativo oriundas de questões complexas trazidas pela pandemia do novo coronavírus, este artigo apresenta um estudo de caso sobre o Labdes Covid-19 e suas relações com o design de informação, pois registrar e dar visibilidade a experimentos como este contribui para o entendimento de iniciativas similares.

O Laboratório de Design Social Covid-19 foi criado com o intuito de conectar iniciativas que objetivassem contribuir para a resolução dessas questões urgentes e seus impactos sobre as populações em situação de vulnerabilidade social na cidade de São Luis - Maranhão.

Para relatar esta iniciativa optou-se pelo método de estudo de caso, por ser adequado para o entendimento de eventos contemporâneos, "quando os comportamentos relevantes não podem ser manipulados" (Yin, 2015, p.13).

Sendo os autores deste artigo participantes ativos da formação e continuidade do Labdes Covid-19, as técnicas de investigação adotadas foram a análise de atas de reuniões, comunicações realizadas em grupos de WhatsApp e o material produzido no perfil da iniciativa no Instagram.

\section{O Laboratório de Design Social Covid-19}

Após uma articulação iniciada em 24 de março de 2020, o Labdes Covid-19 teve sua primeira assembleia; já no dia seguinte, em uma reunião realizada por meio do aplicativo Zoom, na qual estavam presentes profissionais, acadêmicos e estudantes das áreas do Design, Saúde, Direito e Comunicação. Na ocasião, foi apresentado o modelo de Assembleia Projetual do Labdes Desterro e os desafios para adaptação a um formato não-presencial para atender demandas oriundas da crise gerada pela pandemia do Covid-19. 
Foram abordados diversos temas que pudessem ser explorados a partir de soluções de projeto com os membros do laboratório. Adotando uma abordagem aberta e colaborativa, decidiu-se observar as seguintes questões relacionadas à crise da pandemia de Covid-19:

- Como ajudar as pessoas a terem acesso à informação confiável sobre a pandemia?

- Como colaborar com a saúde mental das pessoas em um momento de distanciamento social?

- Como colaborar com o design de artefatos de segurança para aqueles que trabalham em áreas de trabalho essencial?

- Como colaborar com outros grupos que estão atuando na segurança alimentar e de saúde?

- Como colaborar com iniciativas que ajudam aqueles que perderam seus empregos?

- Como colaborar com microempreendedores e trabalhadores informais para a geração de fontes de renda em um momento de parada da economia?

- Como colaborar com a higiene daqueles que não têm acesso à água potável e produtos de higiene como pessoas em situação de rua e pessoas que vivem em condição de pobreza extrema?

As primeiras reuniões foram realizadas pela plataforma Zoom, entretanto, devido às instabilidades e limitações que a ferramenta enfrentava na época, passou-se a utilizar a plataforma Google Meet. A articulação acontecia por meio de três grupos de WhatsApp, nos quais eram levantadas inquietações acerca do inesperado cenário pandêmico. Havia um grupo geral para comunicações de interesse comum a todos, outro de informação que envolvia profissionais e acadêmicos da área da Saúde e um terceiro que englobava pessoas das áreas de Design e Comunicação.

Os questionamentos e as discussões internas levaram à necessidade de buscar informações confiáveis que pudessem ser compartilhadas no Instagram e em formatos replicáveis por mensagens instantâneas.

A apresentação do laboratório foi realizada por meio de um perfil no Instagram criado em 9 de abril de 2020, no qual foram expostos os três principais objetivos da iniciativa, a saber: levantar questões sobre como as medidas tomadas para a contenção do vírus estavam afetando diferentes grupos sociais na cidade de São Luís; buscar parcerias para a execução de projetos relacionados ao tema e divulgar iniciativas já existentes, a fim de conectá-las com seus possíveis colaboradores e beneficiários. Após essa etapa, foram publicados conteúdos informativos sobre a Covid-19 e como a pandemia afetava de forma diferente as diversas classes sociais.

A atuação inicial do laboratório que estava direcionada apenas à produção de conteúdo informativo sobre a pandemia no Instagram passou a ser questionada já no fim do mês de abril daquele ano. Naquele momento, o quadro de problemas sociais havia se agravado e parte dos participantes apontaram para a necessidade da atividade do Labdes Covid-19 servir como 
suporte às questões mais urgentes que ultrapassassem a esfera virtual, como o apoio a entidades que estavam atuando junto às pessoas em situação de vulnerabilidade.

Em 05 de maio de 2020, São Luís se tornou a primeira capital do Brasil a adotar o lockdown (Corrêa, 2020, "São Luís estreia bloqueio total por causa da Covid-19 e exige autorização para circular", para. 1). Essa decisão agravou a situação de insegurança alimentar de diversas comunidades vulneráveis. A partir disso, o laboratório passou a atuar de forma mais efetiva com a campanha Labdes na rua, contribuindo com iniciativas que davam assistência às pessoas em situação de vulnerabilidade. Em uma perspectiva colaborativa e democrática, tendo por base o diálogo, em assembleia, foi definido que o grupo passaria a colaborar com a infraestruturação e divulgação do projeto "A união faz a sopa", iniciativa apoiada por associados do Rotary Club de São Luís que preparava sopas para pessoas em situação de rua.

Por Infraestruturação (Infrastructuring) entende-se como a constituição de infraestruturas sociotécnicas que proporcionem o surgimento de espaços para a cooperação (Delano Rodrigues, 2020). E está vinculada a processos de design que proporcionam "condições efetivamente favoráveis para vários projetos de vida e diversas organizações colaborativas" (Manzini, 2015, p. 151 apud Delano Rodrigues, 2020).

A Infraestruturação é "uma forma específica de design participativo que desenvolve e fornece recursos e experiências sócio-materiais, a fim de constituir vínculos capazes de formar públicos em torno de questões de interesse comum" (Dantec \& DiSalvo, 2013 apud Delano Rodrigues, 2020).

\section{Pandemia, infodemia e o laboratório de design social}

O início da pandemia de Covid-19 era de extrema incerteza. Um contexto expresso pelo excesso de informação sobre precauções, restrições de circulação e recomendações de saúde e segurança e, consequentemente, um quadro crescente de desinformação. Nesse cenário surgiram nossas primeiras assembleias que tinham o objetivo de compreender a complexidade desse cenário, para assim prover dados confiáveis sobre a pandemia que pudessem servir de apoio para os diversos públicos de interesse.

Nesse enfoque, com o perfil do Labdes Covid-19 no Instagram e a articulação da rede de contatos pessoais dos participantes, passou-se a divulgar e acionar pessoas para participar da iniciativa para construir informações confiáveis com pessoas de diferentes áreas, em um cenário "infodêmico". Segundo Duarte e Garcia (2020) o termo infodemia se refere:

a um grande aumento no volume de informações associadas a um assunto específico, que podem se multiplicar exponencialmente em pouco tempo devido a um evento específico, como a pandemia atual. Nessa situação, surgem rumores e desinformação, além da manipulação de informações com intenção duvidosa (p. 1).

Esses rumores estão diretamente ligados à disseminação de desinformação e pode ser entendida como informações falsas (fake news). Tais "informações" eram, e ainda são, 
divulgadas por correntes de mensagens disseminadas em aplicativos de redes sociais como o Whatsapp, Instagram, Facebook, entre outros.

Nesse sentido, o esforço para gerar informação confiável é de extrema importância já que a disseminação de informações falsas caminha de maneira acelerada, pois, como afirmam Garcia e Duarte (2020), "na era da informação, esse fenômeno é amplificado pelas redes sociais e se alastra mais rapidamente, como um vírus" (Garcia \& Duarte, p. 1, 2020).

A diversidade de participantes permitiu articular informações de maneira reflexiva e confiável sobre o enfrentamento da pandemia, em um momento que pouco conhecimento havia sido produzido sobre o assunto. Os temas do material informativo do laboratório foram escolhidos a partir de diversos questionamentos que emergiram no espaço virtual das assembleias, compreendendo as diferentes maneiras que o vírus estava afetando as múltiplas classes sociais. Isso só foi possível pela multidisciplinaridade presente nos discursos dos participantes que vinham de realidades variadas, com diferentes visões de mundo, saberes e experiências.

Frascara (2004) afirma que o design de informação é desenvolvido em duas etapas: a organização da informação e o planejamento de sua apresentação. Por isso, a partir dessa primeira etapa de organização e categorização, partimos para o delineamento de como esses conteúdos seriam compartilhados. Para apresentação desses conteúdos no Instagram, plataforma escolhida por sua popularidade e enfoque imagético, foram definidos primeiro os tópicos mais abrangentes, por ordem de necessidade e urgência, considerados prioritários a necessidade de isolamento físico e, em seguida, as formas de contágio.

A organização dessas informações foi elaborada para serem ilustrativas, didáticas e objetivas; expostas, cada uma, no formato de carrossel ${ }^{1}$, contendo uma ilustração e o tema na capa e, nas páginas seguintes, textos curtos e objetivos, tal fator fora primordial para o delinear o planejamento no ambiente virtual que seria o espaço para promoção da informação. Dessa forma, as ilustrações sempre eram inseridas na primeira imagem do carrossel (capa) com o objetivo de gerar curiosidade em uma rede social que é conhecida justamente pela rapidez de rolagem do feed ${ }^{2}$ e quantidade de informações visuais.

\section{Construindo a identidade do Labdes Covid-19}

A identidade visual do Labdes Covid-19 foi construída pelo grupo de comunicação e design constituído, inicialmente por 7 pessoas em um espaço de três dias. Foram exploradas as discussões sobre a representação do coronavírus desenvolvida pelos ilustradores Alissa Eckert e Dan Higgins, que ajudaram a disseminar o entendimento do vírus e da sua forma de transmissão (Assis, 2020, "Quem desenhou a representação visual do coronavírus", p. 1). Tomando como conceito a disseminação (do vírus, e posteriormente do que pretendíamos fazer: disseminar informações confiáveis) fora possível visualizar um caminho em direção ao

\footnotetext{
${ }^{1}$ Postagem em formato de "álbum" com imagens até 10 imagens em sequência.

${ }^{2} \mathrm{O}$ feed é o local que reúne todas as publicações do perfil e serve como um resumo do conteúdo que você produz. Sua organização, estrutura o conceito e a identidade que você deseja transmitir aos seus seguidores.
} 
desenvolvimento da marca visual do laboratório, que se deu amparado pelo conceito inicial; disseminação, em alusão a algo que se dissemina, que se "espalha".

Os participantes do grupo de comunicação e design geraram várias propostas utilizando ferramentas para dar suporte ao desenvolvimento da marca, que foram apresentadas em reuniões virtuais no app Zoom com as pessoas envolvidas no projeto e refeitas de acordo com os apontamentos realizados por todos - designers e participantes. Vale ressaltar que 0 mesmo percurso metodológico para desenvolvimento da marca visual do Labdes Covid-19 fora replicado para o desenvolvimento das propostas que serão apresentadas adiante.

Para tanto, as reuniões on-line eram iniciadas com um briefing de criação, que consiste em: fazer perguntas, conduzir a pesquisa, reduzir o escopo do briefing e definir mensagens-chaves (LUPTON, 2012). Após algumas rodadas de feedback e deliberações, o conceito fora reforçado e, a partir de uma segunda ferramenta, brain dumping visual (LUPTON, 2012), fora escolhida uma das versões e, por fim, o grupo decidiu seguir com o seu detalhamento.

Figura 2: Reunião virtual para apresentação das primeiras propostas

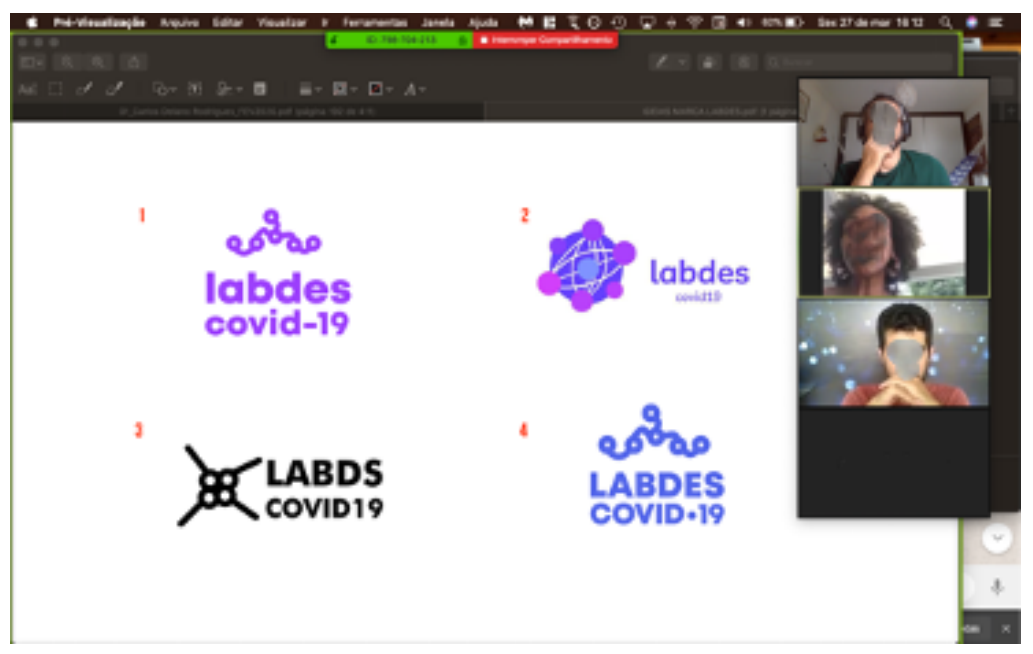

No brain dumping visual reuniu-se o máximo de símbolos, ícones, palavras possível para uma análise visual a partir da representação que mais aproximava do conceito inicial. Para o símbolo, optou-se por trabalhar a abstração do modelo de visualidade do vírus proposto por Eckert e Higgins. O símbolo explora a própria característica emergente do laboratório, com sua formação que cresce ou diminui dependendo das questões que surgem no grupo. Para a tipografia, foi escolhida uma fonte geométrica sem serifa, com caracteres bem limpos, de forma a priorizar sua acessibilidade. A paleta de cores é composta por tons mais frios como azul e roxo, buscando um conjunto de cores análogas que estabelecem uma coerência para a identidade visual. 
Figura 3: A marca visual definida e postagens no feed do Instagram

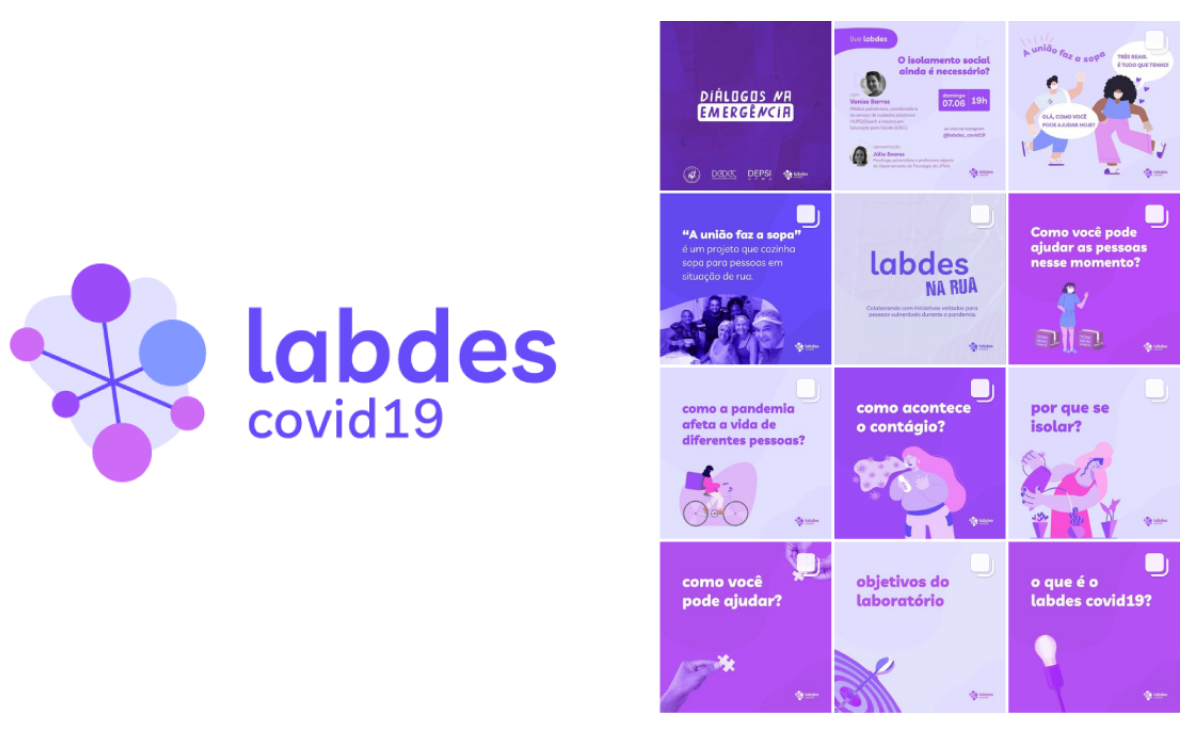

A fim de comunicar à comunidade sobre o laboratório, as primeiras postagens realizadas abordaram a definição do projeto e seus objetivos. O Labdes Covid-19 foi definido então como um laboratório de design social criado com o intuito de conectar iniciativas para solucionar questões urgentes relacionadas ao coronavírus na cidade de São Luís.

Nesse momento foi usada como base para desenvolvimento das postagens a identidade visual da marca do Labdes Covid-19, para dar segmento ao planejamento das postagens, assim como com o uso de ilustrações e alguns registros fotográficos de ações que surgiram durante a pandemia (que serão apresentadas a seguir). As informações presentes nas postagens em cada um conteúdo da página no instagram eram geradas e levantadas a cada reunião com os participantes, sintetizadas e adaptadas para o formato instagram e em seguidas desenvolvidas pelos participantes designers do laboratório. Esse mesmo modelo fora repassado para as demais iniciativas.

Em síntese, os objetivos divulgados foram: (1) levantar questões sobre como as medidas tomadas para contenção do vírus estavam afetando diferentes grupos sociais; (2) buscar parceiros para a execução de projetos em andamento e (3) divulgar iniciativas já existentes a fim de conectá-las com seus possíveis beneficiários e colaboradores com o objetivo de disseminar informação confiável sobre a pandemia.

\section{Campanhas de conscientização}

O grupo de participantes do Labdes Covid-19 era diverso, com pessoas que podiam estar em isolamento, trabalhando em formato home office, mas também trabalhadores de atividades essenciais que lidavam diariamente com a ansiedade e medo do contágio pelo coronavírus. Essa multiplicidade de realidades vividas por seus membros inspirou o desenvolvimento de uma campanha para discutir os problemas enfrentados. Não obstante, identificou-se o quanto a 
pandemia trouxe complicações emocionais a todos, inclusive aos próprios participantes do Labdes Covid-19.

A campanha de conscientização e reflexão sobre a pandemia foi elaborada a partir do levantamento de quatro questões centrais, sendo elas: "Por que se isolar?", "Como acontece o contágio?", "Como a pandemia afeta a vida de diferentes pessoas?" e "Como podemos ajudar as pessoas nesse momento?".

As perguntas serviram como base para construção do material visual compartilhado no perfil do Instagram do laboratório, utilizando postagens em carrossel (Figuras 4 e 5) para estruturação dos materiais na seguinte ordem: questão e ilustração, como primeira imagem; seguida por textos curtos sobre a questão levantada e finalizando com uma recomendação ou reflexão. As ilustrações utilizadas foram criadas para dar suporte ao texto e reforçar a mensagem, explorando situações comuns no dia a dia durante a pandemia.

Figura 4: Publicação realizada em formato de carrossel
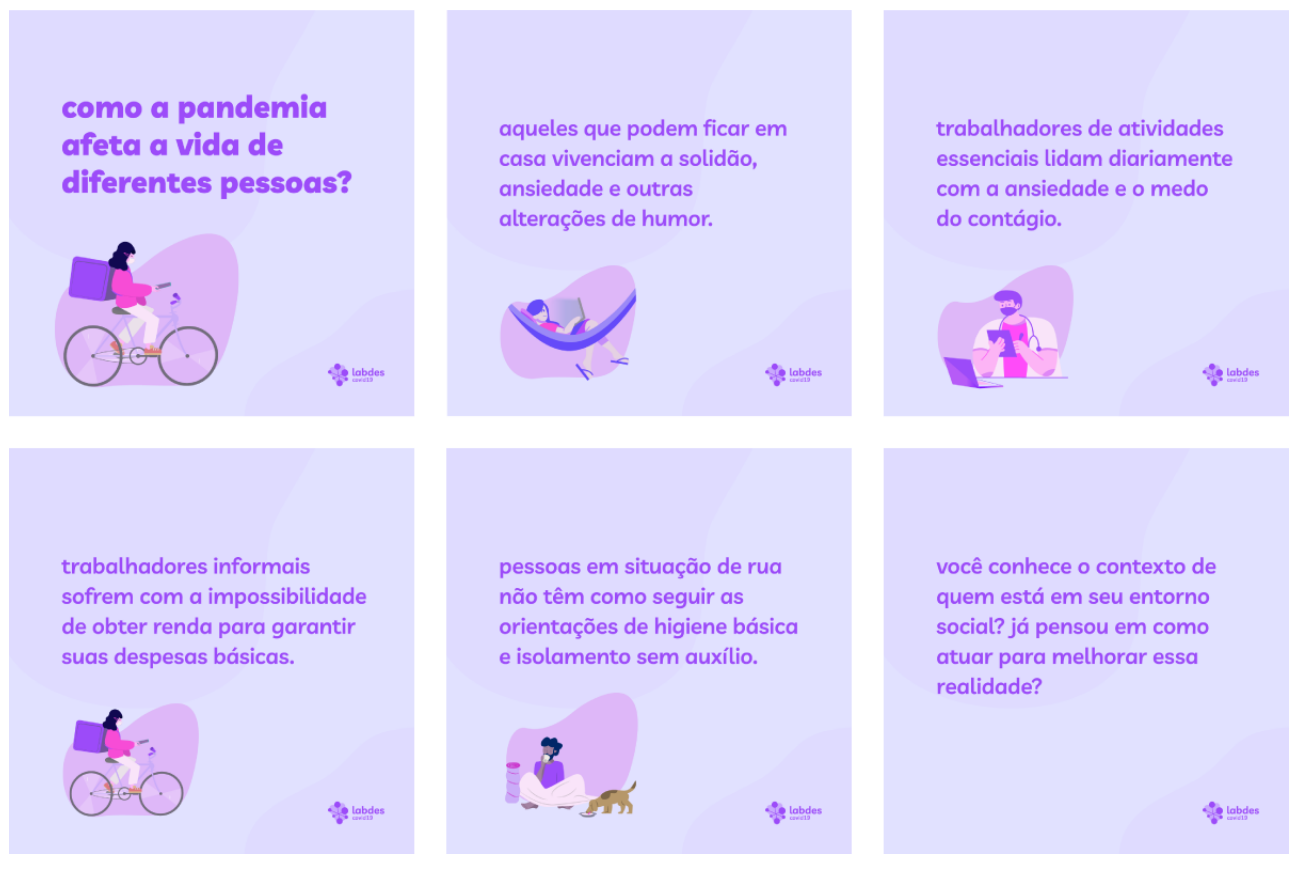

\section{Campanha "A União Faz a Sopa"}

Com o intuito de combater a situação de insegurança alimentar durante a pandemia, foi proposta a campanha "A União Faz a Sopa", com o objetivo de arrecadar recursos financeiros, ingredientes e materiais que auxiliassem na produção e entrega de comida para pessoas em situação de rua de São Luís.

O material para arrecadação de doações foi desenvolvido a partir do levantamento de informações necessárias para que os públicos compreendessem de que forma poderiam contribuir. Nesse material foram usadas formas, marcadores e pesos diferentes, a fim de hierarquizar as informações e garantir a compreensão do conteúdo pelos possíveis doadores e voluntários interessados em ajudar. 
Figura 6: Material para arrecadação de doações para o projeto "A União Faz a Sopa"
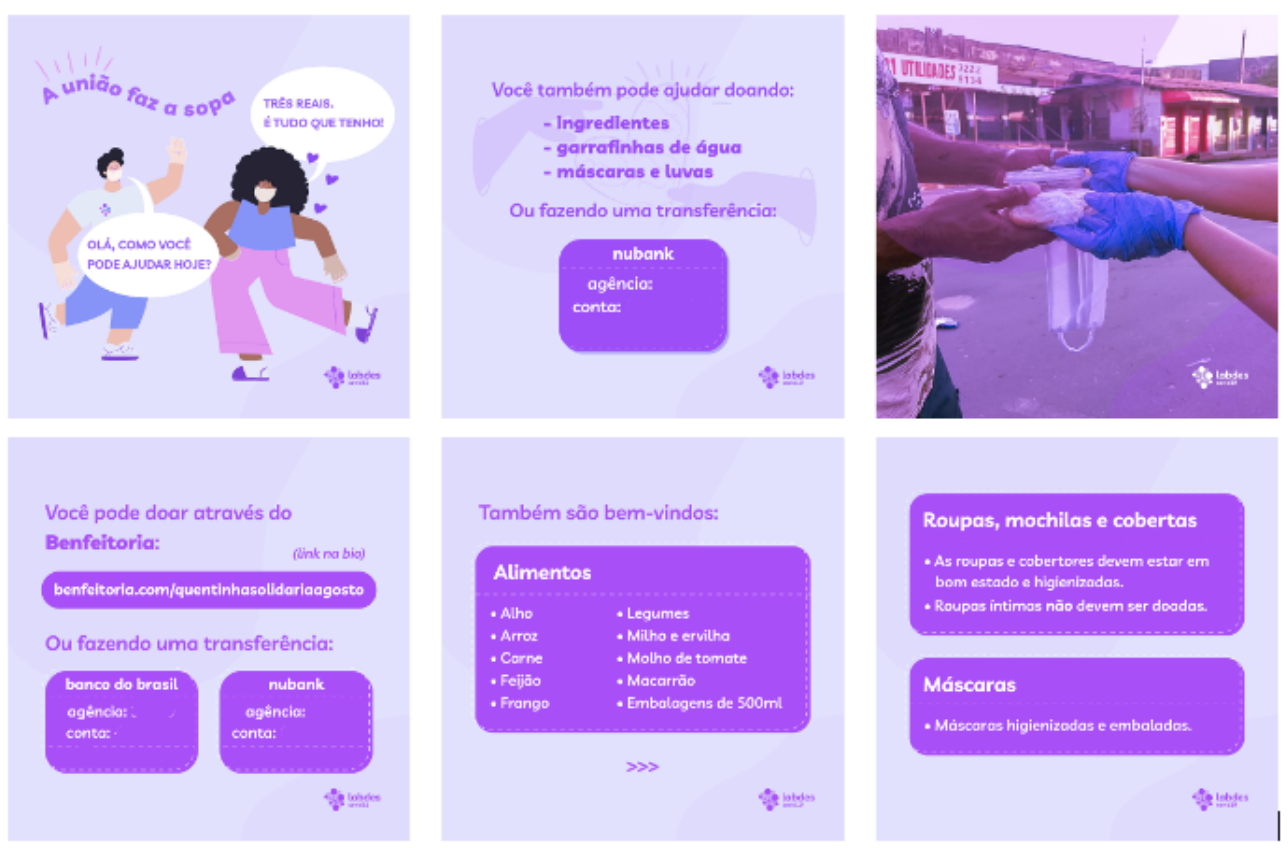

\section{Quentinha Solidária}

Inicialmente, a divulgação do projeto era realizada por meio do perfil do laboratório no Instagram mas, à medida que o número de voluntários e doadores para essa ação específica cresceu, surgiu a necessidade de criar uma identidade visual própria para que o projeto ganhasse autonomia. Assim nasceu o "Quentinha Solidária", cujo nome e identidade visual foram desenvolvidos pelos membros do curso de Design da UFMA, participantes do Labdes Covid-19, durante o mês de agosto de 2020 , no mesmo formato utilizado para o desenvolvimento da marca do Labdes Covid-19, através de reuniões on-line. Entretanto, ressaltou-se que, para a proposta da marca visual do projeto Quentinha Solidária, as reuniões contaram com a presença dos participantes do projeto quentinha e assim a tomada de decisão contou com a colaboração dos atores envolvidos.

Figura 7: Marca visual criada para o projeto "Quentinha Solidária"

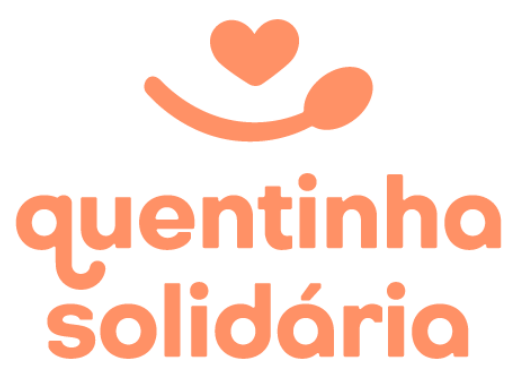

O processo de criação da marca aconteceu de forma participativa, utilizando as ferramentas citadas anteriormente, considerando o objetivo do Quentinha Solidária enquanto grupo que atendia pessoas em situação de rua de São Luís, servindo refeições. Para a validação da 
marca, foi feita uma reunião virtual com seus membros, promovendo-se um espaço dialógico onde identificamos que a mesma satisfazia o objetivo de comunicar o propósito do grupo.

Figura 8: Postagens para divulgação do projeto "Quentinha Solidária"

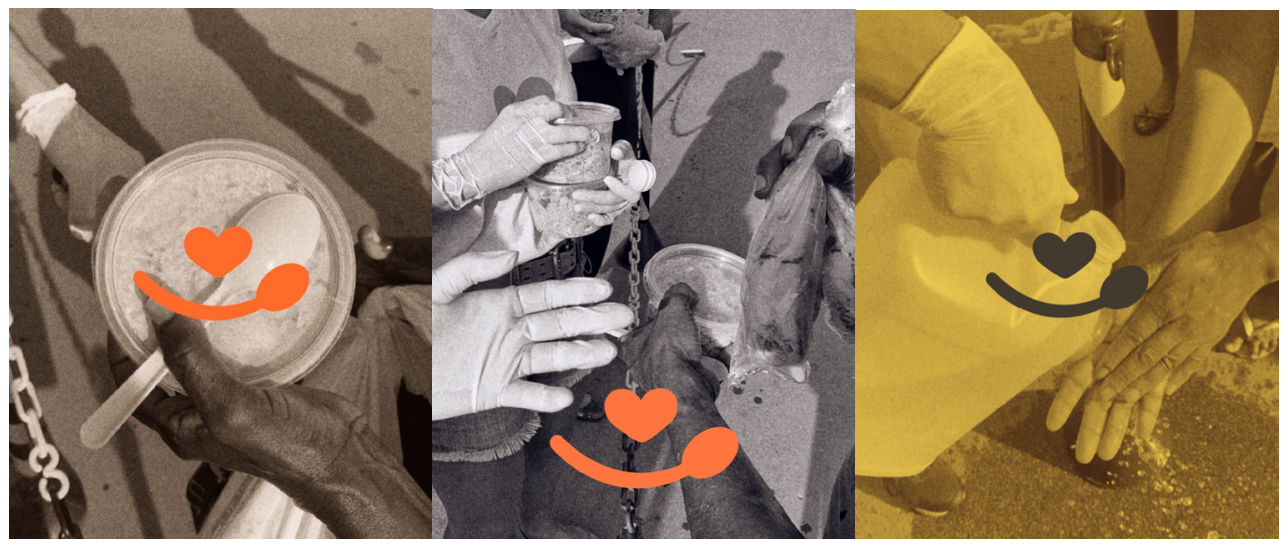

A criação da identidade visual acompanhada de seu manual e orientação possibilitou, ao grupo de pessoas que estavam responsáveis pela execução do projeto, ter autonomia para se comunicar com seu público com clareza e objetividade, criando seu próprio material para divulgação de campanhas e ações, agora como um grupo independente do laboratório. $\mathrm{O}$ planejamento, divulgação e gestão dos conteúdos no instagram do projeto ficaram sob a responsabilidade de designers e participantes do projeto quentinha.

\section{Considerações finais}

O propósito do Labdes Covid-19 foi o de conectar pessoas e iniciativas que contribuíssem com soluções para reduzir o impacto da pandemia de covid-19. É possível afirmar que os objetivos iniciais de construção do espaço de Assembleia Projetual e a implementação de ações foram alcançados no que tange o desenvolvimento de campanhas que surgiram em um cenário pandêmico, bem como proporcionar informações confiáveis a partir de uma rede virtual, amparadas por práticas em design.

O conhecimento do design da informação teve papel preponderante no desenvolvimento das ações de produção de material informativo a respeito dos cuidados a serem tomados durante a pandemia, principalmente com o apoio à segurança alimentar, colaborando com o surgimento do Quentinha Solidária, uma comunidade autogerida que continua atuando como rede de apoio às pessoas em situação de rua e que atualmente planeja e desenvolve suas ações com os próprios integrantes de forma autônoma.

É possível inferir que os desdobramentos do projeto inicial ganharam força a cada atividade desenvolvida apoiadas por práticas em design, partindo da confiança estabelecida ao tangenciarmos pessoas em um cenário com tantas incertezas. O grupo cresceu e ainda cresce tanto em práticas, objetivando auxiliar em outras propostas e iniciativas locais, quanto em número de participantes interessados em ingressar no laboratório. 
Conseguimos destacar um modelo de trabalho e prática de design no ambiente remoto que facilita a colaboração de agentes com objetivos em comum, no nosso caso de assembleias projetuais, ou seja, ganhos secundários podem ser observados a partir de uma breve análise do laboratório.

É certo que iniciativas como esta favorecem o fortalecimento da atuação da sociedade civil, especialmente em cenário de crise, contribuindo com informações relevantes, confiáveis e atividades cujo motriz é conectar pessoas para a solução de problemas coletivos, além de promover engajamento da comunidade, bem como promover o design enquanto prática para atividades sociais.

O Labdes Covid-19 surgiu como iniciativa que pudesse responder às questões trazidas pela pandemia causada pelo coronavírus, em um cenário de incertezas, a partir da convergência de ideias de pessoas de diversas áreas que buscavam, de alguma maneira, minimizar os impactos do contexto em São Luís do Maranhão. Em uma proposta de participação democrática e colaborativa, usando os princípios do design participativo, os objetivos do laboratório foram se constituindo e, conforme avançava, verificou-se a necessidade de um novo planejamento de ações, sem que se perdesse de vista o propósito inicial.

Constatou-se a necessidade de ampliação dos objetivos, acrescentando o direito à cidade como um foco e, do embrião gerado pelo Labdes Covid-19, foi construído um projeto de extensão na Universidade Federal do Maranhão, o Labdes Cidade.

\section{Referências}

Assis, T. (2020). Quem desenhou a representação visual do coronavírus | VEJA SÃO PAULO. Retrieved February 20, 2021. Obtido em https://vejasp.abril.com.br/blog/arte-aoredor/desenho-coronavirus-ilustradores/

Ballon, P., \& Schuurman, D. (2016). Living Labs: Concepts, Tools and Cases. SSRN Electronic Journal. https://doi.org/10.2139/ssrn.2642754

Concilio, G. \& Rizzo, F. (Org.) (2016). Human Smart Cities: Rethinking the Interplay between Design and Planning (Urban and Landscape Perspectives). Milan/Bologna, IT: Springer.

Corrêa, C. (2020). São Luís estreia bloqueio total por causa da Covid-19 e exige autorização para circular - O Globo - Sociedade. Retrieved October 13, 2020. Obtido em https://oglobo.globo.com/sociedade/sao-luis-estreia-bloqueio-total-por-causa-da-covid-19exige-autorizacao-para-circular-24410765

Delano Rodrigues, Carlos; Franzato, Carlo; Almendra, R. A. (2017). Sustainability of Social Design Laboratories: Infrastructuring of publics and Micro-planning in the development Design Networks. In 23nd International Sustainable Development Research Society Conference, School of Science and Technology, (pp. 610-625). Bogotá.

Delano Rodrigues, C. (2020). O Design em Assembleias Projetuais: Desafios e alternativas para a sustentabilidade do projeto participado em bairros vulneráveis [Tese de doutorado]. Faculdade de Arquitetura. Universidade de Lisboa, Portugal.

Frascara, J. (2011). ¿Qué es el diseño de información? (1st ed.). Buenos Aires: Ediciones Infinito. 
Garcia, Leila Posenato; Duarte, Elisete. Infodemia: excesso de quantidade em detrimento da qualidade das informações sobre a COVID-19. Epidemiol. Serv. Saúde, Brasília, v. 29, n. 4 , e2020186, 2020. Obtido em <http://www.scielo.br/scielo.php?script=sci_arttext\&pid=S223796222020000400100\&lng=en\&nrm=iso>. access on 14 May 2021. Epub Sep 07, 2020. http://dx.doi.org/10.1590/s1679-49742020000400019.

Lutpon, Ellen (2012). Intuição, ação, criação. Graphic Design Thinking. $1^{\mathrm{a}}$ ed. GG.

\section{Sobre os autores}

Agnes Milen Guerra, UFMA, Brasil, agnes.guerra@discente.ufma.br

Bruna Cibelle de Andrade Abreu, UFMA, Brasil, bruna.cibelle@discente.ufma.br

Carlos Delano Rodrigues, UFMA, Brasil, carlos.delano@ufma.br

Israel Lucas Sousa Silva, UFMA, Brasil, israellucas.sousasilva@gmail.com

Jackeline Mendes Pereira, UFMA, Brasil, jackeline.mp@discente.ufma.br

Rafael Ricarte de Souza, UFMA, Brasil, rafael_ricart@me.com 